\section{Decision making in the critically ill neonate}

SIR

Senior members of a teaching hospital have presented the results of a study ${ }^{1}$ that, I would like to suggest, should not have been performed for a number of reasons:

1. Women in the 2nd and 3rd trimester of pregnancy are in need of reassurance that all is well, and that they may expect a normal baby. Even if randomized, it must be unsettling for an expecting mother to be induced to visualize the scenario of a hypothetical severe malformation, more so since $13.5 \%$ of the participants came from the infertility clinic, where they had been exposed to some of the darker aspects of reproduction. The women did participate voluntarily, but they were recruited during their routine medical visits, that is, their medical care was not sufficiently separated from their commitment to the research project.

2. Multiple choice and "one to twoword factual answers" are absolutely disanalogous to real life tragic decisions which are preceded by intense consultation, deliberation and advice. It seems frivolous to equate a test answer with the highly dramatic situation which the authors acknowledge to be characteristic of "critically ill neonates".

3. What kind of knowledge has been gained with regard to "times of overwhelming stress"? It needed no large survey to confirm that cultural and religious attitudes weigh heavily in dramatic life/death decisions. Statistics will not help in any way to short-cut the ethical deliberation that needs to be exhaustive enough to probe all values involved in actual neonatal decision making.

4. The methodology is flawed, the conclusions are trivial, with hardly any predictive power. And yet, the paper acknowledges the support of "generous" material and personnel resources. Does this not show a deficient allocation policy?

What did the local research ethics committee have to say? The paper does not mention submitting to any ethical review by the institution's Institutional Review Board (IRB) or Local Research Ethics Committe (LREC). Shouldn't the editors accepting such a paper offer some clarity on the research ethics involved? This is non-therapeutic research that illustrates how (potentially) harmful investigative methods will not yield ethically acceptable conclusions.

\section{References}

1 Hammerman C et al. Decision making in the critically neonate: cultural background $\mathrm{v}$ individual life experiences. fournal of Medical Ethics 1997;23:1649.

MICHAEL H KOTTOW, MA, MD Professor, Faculty of Philosophy, University of Chile

\section{Response to Kottow}

SIR

We would like to thank Profesor Kottow for sharing his concerns regarding our article, ${ }^{1}$ and we appreciate this opportunity to respond. Firstly, we do not believe that there was any - even subtle - pressure upon our subjects to participate in the research by virtue of the fact that they were recruited during clinic visits. They were recruited by volunteers who made it clear that they were unassociated with the medical and/or nursing staff of the clinic. Their doctors were completely unaware of the patients' participation or lack thereof in responding to the questionnaire. Several women preferred not to respond and were quite free to do so.

Furthermore, while it is certainly true that pregnant women in the 2 nd and 3rd trimester are anxious about their pregnancy, our questionnaire was preceded by a carefully worded disclaimer reassuring them that the questions were hypothetical, stressing that the overwhelming majority of pregnancies remain uncomplicated and that the following questions were TOTALLY UNRELATED to her pregnancy. The questions themselves were formulated by a team consisting of a neonatologist, an obstetrician and a medical social worker, with careful consideration given to these delicate issues. Both the disclaimer and the questions were reviewed by a psychologist before the study was begun. The volunteer, who approached each potential subject, further reassured her of the hypothetical nature of the questions and the fact that they were totally unrelated to her pregnancy.

The issue of one to two word factual answers being able to represent real life tragic decisions is one over which we too agonized. Unfortunately, or rather fortunately, such research cannot be done in real time. We are well aware of, and have related to, the limmitations of this approach in our disc $\overline{\mathrm{TS}}-$ sion. Nevertheless, questionnaifes such as we used, albeit flawed, ara well accepted technique in this arexs̄of research. ${ }^{2-4}$

We clearly agree that ethical de्बi-

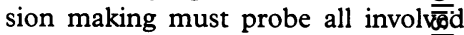
values. We had absolutely no intenti to "short-cut ethical deliberation" But intended, rather, to help staff involk़d in these deliberations to understagtd better the decision-making process and to sensitize them during the्efr "exhaustive probing" with the pare during stress.

As to the alleged triviality of o $\mathrm{ur}$ conclusions, again we must disagrae. We are not merely confirming that cultural and religious values are portant. Statistics enable us to grade the relative importance of variogs parameters. It was not inherently obvious to any of us that cultural background would supersede subsequent, possibly poignant, life expe्gुiences in importance in the decisionmaking process.

Professor Kottow's implied grọcism of resource allocation is equatty inappropriate, in our opinion. I由 "generous support" which was acknowledged, was a private doniation from my cousin (note same last nan which was used to fund the transtetions of the questionnaire into Arabic and Russian languages large sums by any criteria.

We did, of course, seek permiss海 from our local institutional review board (Helsinki Committee), whi్ was granted.

In conclusion, we feel that methodology was well thought oujt, carried out with ethical propriety a $\mathrm{d}$ in no way trivial. On the contrary, whe remain convinced that these data $g_{n}$ improve staff sensitivity and awareness in dealing with parents during timeș stress.

\section{References}

1 Hammerman C, Kornbluth E, Leffe O, Zadka P, Aboulafia A, Eidelman A Decision making in the critically-ill neonate: cultural background $v$ individual life experiences. Fournal of Medical Ethics 1997;23:164-9.

2 Todres ID, Guillemin J, Grodin \&, Batten D. Life saving therapy for newborns: a questionnaire survey in the state of Massachussetts. Pediatitics 1988;81:643-9.

3 Segal S. Ethical issues presented children with congenital anomales. Seminars in Perinatology 1992;16:36972.

4 Byrne P, Tyebkhan J, Laing LM. Ethical decision-making and neonatal resuscitation. Seminars in Perinatology 1994;18:36-41. 